\title{
Editorial
}

\section{Global Ecology, Global Health, Ecohealth}

An increasing number of ecological, biological, and other natural scientists regard the trajectory for global civilisation as ominous. A recent high-level meeting commemorating the 350th anniversary of the Royal Society highlighted the need to resist sinking into pessimism in the face of overwhelming threats (Howard and Chamberlain 2011). The list of these threats is long, and prominent is an ongoing decline in the number, quantity and quality of ecosystems. Many of these are threatened by direct or indirect human action, such as coral blasting, wildfires, introduced pests, and the exchange of forests for biofuel plantations, or the loss of populations of critical keystone species such as amphibians or bats, which may cause collateral damage to health or food security.

Some public health workers have warned that the risks for public health are dire unless these trends of worsening harm to our ecological support mechanisms are reversed (McMichael and Butler 2011). However, most forecasts for future health remain determinedly upbeat. For example, the United Nations Population Division has this year increased its forecast of the maximum human population likely this century from 9 to 10.1 billion. If realised, this would represent a tenfold increase in our numbers in only three centuries. The fine print of this UN report is unlikely to state that this projection assumes no massive human catastrophe, such as large-scale famine, war, or epidemic; however, such assumptions are implicit. Denial of planetary-wide limits to growth also occurs among those demographers who predict a substantial rise in human life expectancy.

To those with an ecological background, the idea that humans are the one species resistant to large-scale checks on population growth is naive, yet it's strong, even dominant in the social science literature. In 1988, when global human population had passed five billion, the editor of the
Population and Development Review rejected warnings that limits to growth were nearing (Demeny 1988). This article was representative of the "cornucopian enchantment" period which started in the late 1970s (Butler 2007); traces of which still persist. In 2010, global population size was not a topic at the annual meeting of the Population Association of America, causing commentators to note that "the problem has become a bit passé". Perhaps this is part of the well-substantiated human trend for excessive optimism, a trait probably useful to maintaining well-being in the face of adversity, but certainly dysfunctional if it generates excessive risk-taking.

Fusing these grand themes of demography, ecosystem change and health is one of the roles of our journal, EcoHealth, and the International Association for Ecology and Health. Our field builds on the growing perception by some within public health that the global ecosystem, and hence global health, may be in peril. It is as if civilisation is aboard a jet plane, and those most responsible for the health of its passengers are beginning to fear an approaching storm. These health risks from stressed ecological systems extend far beyond those of emerging zoonoses, to include a lost library of potential therapeutics, and less contact with the wild. They threaten the foundations of human well-being at the planetary level (McMichael and Butler 2011).

Within the disciplines of medicine and public health, very few organisations have formed in response to these warnings, even though they increasingly pepper the natural science literature. There are organizations, such as the International Society of Doctors for the Environment and the International Society for Environmental Epidemiology (ISEE) which cover some of these issues but perhaps focus on more traditional environmental health risks.

A broader view would include not only the climate, but the price of energy, the cost of food, and the livelihood, 
well-being and ultimately health of billions of humans. These interacting, coalescing problems could also enhance violent conflict. The International Physicians for the Prevention of Nuclear War (IPPNW), formed in the 1980s during the depth of the late phase of the Cold War, has been associated with two journals which recognise peril to global public health. However, the ecological issues remain. Similarly, groups which promote global social justice, generally framed as the social determinants of health, also have a role to play in influencing the public health agenda. Indeed, there is increasing recognition within such groups that issues such as climate change will have their greatest impact upon the poor and that the attitudes which drive "environmental brinkmanship" are rooted in habits and norms that reveal privilege for some and contempt for the poor. Yet, few in this school are likely to divert their primarily social focus to an eco-social one, despite growing appreciation that the scarcity of environmental and ecological resources influences the "tightness" of norms and social behaviour.

EcoHealth cannot be the sole umbrella under which health workers explore the myriad dimensions that connect planetary ecology and health. But, there is a clear need for the work of the IAEH and our journal in thinking systemically about the damage which is being done to our planet, in the same way that some in Western medicine now think more holistically about the human body and its milieu.

Finally, just as it is important to retain hope in individual patients, it is also vital not to sink into gloom over the prognosis of our planet and its human cargo. People are beginning to reconnect with the ecosystems which for too long they have viewed as separate. Technological advances have seen the production of aquaculture grow to approximately half that of the oceans. Despite the risks of climate change and growing regional water scarcity, ample food exists to avert global famine. New technologies to generate energy and desalinate water are developing. An increasing fraction of "external" water is traded, enabling large populations to survive in some arid regions. This could be sustainable if such desert dwellers trade virtual water for solar energy. Lastly, with enough leadership, the recently forecast maximum population of 10.1 billion for 2100 could be lowered by almost two billion using human rights based methods with more female education (Das Gupta et al. 2011). But, if these and similar solutions are to be developed and practised then far more workers concerned with human health must become literate and concerned about these issues. This journal can help to fill that niche.

Colin D. Butler

National Centre for Epidemiology and Population Health, College of Medicine Biology and Environment,

Australian National University, Building 62, Mills Rd, Canberra, ACT 0200, Australia

e-mail: colin.butler@anu.edu.au.

Philip Weinstein

Barbara Hardy Institute,

University of South Australia, Adelaide, SA, Australia

\section{REFERENCES}

Butler CD (2007) Globalisation, population, ecology and conflict. Health Promotion Journal of Australia 18:87-91

Das Gupta M, Bongaarts J, Cleland J (2011) Population, poverty, and sustainable development: a review of the evidence, Washington, DC: The World Bank

Demeny P (1988) Demography and the limits to growth. Population and Development Review 14:213-244

Howard JAK, Chamberlain M (2011) The sustainable planet: opportunities and challenges for science, technology and society. Philosophical Transactions of the Royal Society A 369:17151718

McMichael AJ, Butler CD (2011) Promoting global population health while constraining the environmental footprint. Annual Review of Public Health 32:179-197

Published online: December 16, 2011 